\title{
Herbal Medicine: A Survey of use in Moroccan Surgical Patients.
}

\author{
Sidi Driss El Jaouhari*, Mohammed Meziane, Reda Touab, Abde lhamid Jaafari, Jaafar Salim Lalaoui and \\ Mustapha Bensghir \\ Department of anesthesiology and critical care, University of Mohamed V Souissi, Morocco
}

Submission: : December 28, 2017; Published: January 29, 2018

*Corresponding author: Sidi Driss El jaouhari, Department of anesthesiology and critical care, Military hospital Mohamed V, Faculty of medicine and pharmacy, university of Mohamed V Souissi, Rabat, Morocco. Tel: +212661212409; Email: sidijhr@gmail.com

\begin{abstract}
Background: The popularity of herbal medicine (HM) is increasing worldwide and its use is probably more frequent in patients undergoing surgery. The aim of our survey is to explore the use of HM in adult surgical patients.
\end{abstract}

Materials and Methods: single-center prospective survey at department of anesthesiology of Mohammed V Training Military Hospital, Rabat, Morocco, over a period of 5 months. In addition to socio-demographic and herbal use data, other variables included types and the mode of HM consumption, the reasons of use, perceived side effects and perceived efficacy of HM.

Results: A total of 800 eligible participants were approached preoperatively to complete the survey. The mean age of our patients was 49.02 +/- 16.81 years. Among those patients, (50.9\%) were women and (49.1\%) were men. 206 patients (25.8\%) admitted to using HM and (13\%) of the study population has consumed herbal medicine in the week prior to the consultation. The patients also consumed Oregano (29.7\%), Fenugreek (16.1\%), Verbena (10.2\%), Rosemary (9.7\%) and Chamomile (9.7\%). The main source of information found in our study was family members with a rate of $34 \%$, while cultural and religious beliefs are the main reasons for the consumption of medicinal plants

Conclusion: A significant proportion of presurgical patients use HM in our survey. Because of the potential for side effects and drug interaction, it is important for anesthetists to be aware of their use.

Keywords: Herbal medicine; Presurgical patients; Anesthesia; Complications; Drug interactions

\section{Introduction}

Herbal medicine (HM) has been defined as a use a plantderived substance for health purposes [1]. The popularity of $\mathrm{HM}$ is increasing worldwide. According to 3 extensive surveys performed in USA, Australia and England, $12 \%$ of the adult population use herbal medications [2-4]. In Germany, tens of millions of prescriptions are written for herbal medicines each year [5]. In African society, HM play a crucial role in the health care system of many countries. According to Falodun et al. [6] 80\% of Africans has been identified as herbal remedy users. The use of $\mathrm{HM}$ is probably more frequent in patients undergoing surgery [7]. Morbidity and mortality associated with herbal medications may be more likely in the perioperative period because of the polypharmacy and physiological alterations that occur [8-11]. Therefore, anesthesiologists and surgeons must be aware of this importance of this topic for better management of this population [12]. The aim of our survey is to explore the use of HM in adult surgical patients.

\section{Methods}

After obtaining approval from our hospital's Ethics Committee. We performed a single-center prospective survey at department of anesthesiology of Mohammed V Training Military Hospital, Rabat, Morocco. We focus to study herbal medical consumption of adult patients undergoing elective surgery over 5 month's period (from January to May 2017). Patients were seen in pre anesthetic consultation one week prior to surgery. We excluded: children, emergency surgery, patients with dementia or unconscious. A one-page questionnaire was handed out to the patients after they received information about the study and gave their consent to participate to the survey. Literate respondents filled the questionnaires themselves while illiterate ones had the questionnaire administered to them by medical residents. The different items of the questionnaire were concerned about sociodemographic and herbal use data (Names of locally available herbs and herbal remedies), medical background, clinical diagnosis, 
presence or absence of concomitant medical prescriptions. The last part of the questionnaire was about types and mode of HM consumption, the reasons of use, perceived side effects and perceived efficacy of HM. Statistical analysis was performed using SPSS software version 20 . We performed a descriptive analysis with quantitative variables expressed as mean $+/$ - standard deviations and qualitative variables as number and percentage. Differences in demographic characteristics and medical background between HM users and non-users were assessed using Chi2 or Fisher test for qualitative variables or Student $t$ tests or Mann- Whitney $U$ tests for quantitative variables. The significance level was set at 95\% $(\mathrm{P}<0.05)$.

\section{Results}

A total of 800 eligible participants were enrolled to the survey. The mean age of our patients was $49.02+/-16.81$ years. Among those patients, 407 were women (50.9\%) and 393 were men $(49.1 \%$ ) with sex ratio (male/female) of 0.96 . Of the 800 respondents, 206 patients admitted to use of HM giving a rate of $25.8 \%$. Out of these, 104 patients $(13 \%)$ have consumed herbal medicine within week prior to the surgery. More details on demographic characteristics and medical background of our patients are shown in Table 1. In our survey, 52 patients (6.5\%) were illiterate, 154 patients (19.25\%) had a primary level, 423 patients $(52.87 \%)$ had a secondary level and 171 patients (21.38\%) had an academic level. For users of HM, the majority were illiterate (46\%), 73 patients (35.5\%) had a primary level, 30 patients $(14.5 \%)$ had a secondary level and 8 patients $(4 \%)$ had an academic level. The five most frequently herbs used were: Oregano
(29.7\%), Fenugreek (16.1\%), Verbena (10.2\%), Rosemary (9.7\%) and Chamomile (9.7\%) (Figure1). Patients taking herbal medicine often consumed more than one type of product. In our survey, the majority of patients using medicinal plants were candidate of abdominal surgery (33.5\%) and ophthalmic procedures (18.2\%). $22.8 \%$ of consumers use plants for the current surgical pathology.

Table 1: Demographic characteristics and medical background of our patients.

\begin{tabular}{|c|c|c|c|}
\hline & $\begin{array}{c}\text { Non-Users of } \\
\text { HM N=594 } \\
\text { Mean+/-SD } \\
\text { or n(\%) }\end{array}$ & $\begin{array}{c}\text { Users of } \\
\text { HM N=206 } \\
\text { Mean+/-SD } \\
\text { or n(\%) }\end{array}$ & $\begin{array}{c}\text { Total N=800 } \\
\text { Mean+/-SD } \\
\text { or n(\%) }\end{array}$ \\
\hline Mean Age (years) & $48,04+/-17.72$ & $\begin{array}{c}51,83+/- \\
13,53\end{array}$ & $\begin{array}{c}49,01+/- \\
16,81\end{array}$ \\
\hline BMI & $24.74+/-4.32$ & $24.60+/-4.19$ & $24.70+/-4.28$ \\
\hline Sex (\%) & & & \\
\hline Female & $257(43.3 \%)$ & $150(72.8 \%)$ & $407(50.8 \%)$ \\
\hline Male & $337(56.7 \%)$ & $56(27.2 \%)$ & $393(49.2 \%)$ \\
\hline Diabetes (\%) & $89(15 \%)$ & $49(23.8 \%)$ & $138(17.3 \%)$ \\
\hline HBP (\%) & $87(14.6 \%)$ & $46(22.3 \%)$ & $133(16.6 \%)$ \\
\hline Coronary Artery & $11(1.9 \%)$ & $2(1 \%)$ & $13(1.6 \%)$ \\
\hline Disease (\%) & $3(0.5 \%)$ & $2(1 \%)$ & $5(0.6 \%)$ \\
\hline Kidney Injury (\%) & $10(1.7 \%)$ & $7(3.4 \%)$ & $17(2.1 \%)$ \\
\hline CoPD (\%) & $10(1.7 \%)$ & $9(4.4 \%)$ & $19(2.4 \%)$ \\
\hline Heart Failure (\%) & &
\end{tabular}

HM: Herbal Medicine; SD: Standard Deviation; BMI: Body Mass Index; HBP: High Blood Pressure; COPD: Chronic Obstructive Pulmonary Disease

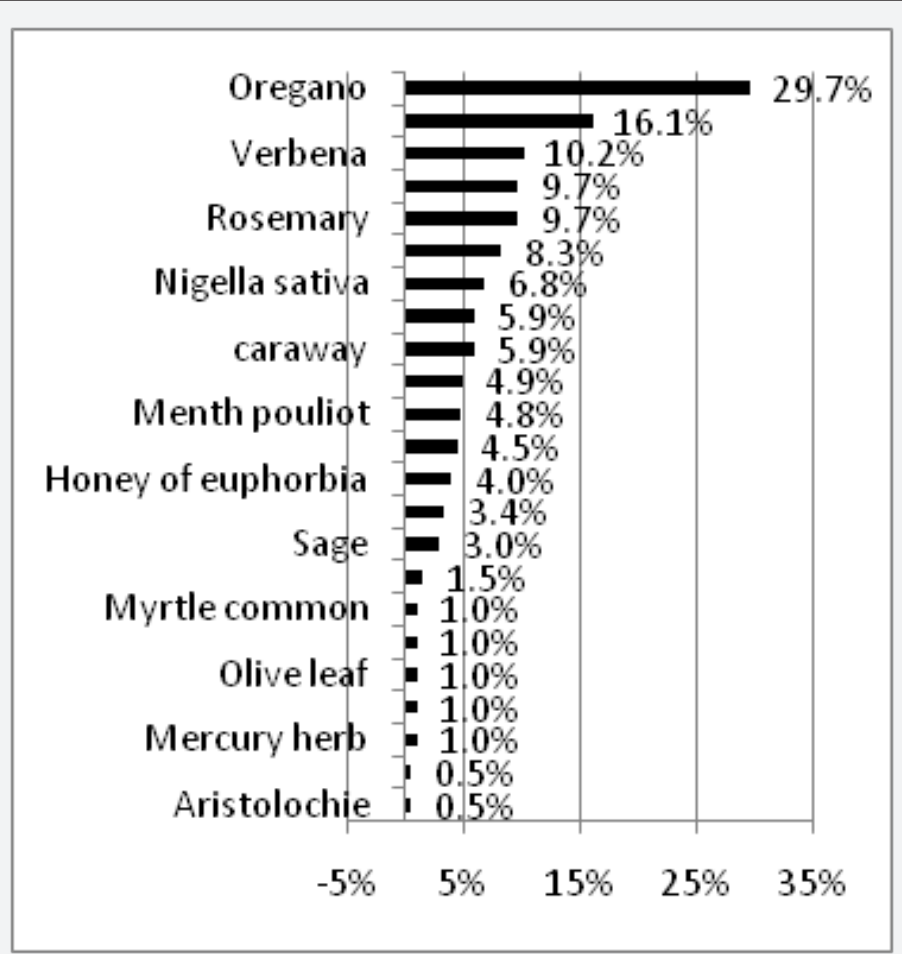

Figure 1: Prevalence of use of medicinal plants in patients admitted for pre-anesthetic consultation. Some patients reported more than one herbal medicine use. 
Most patients were using HM for chronic problems (77.2\%): functional colopathy (42\%), stress and sleeping problems (20\%), to improve concentration (4.8\%), energy (3.8\%) memory (3.8\%) and general health $(2.8 \%)$.

Patients were asked to note where they had learnt about the HM therapy they used/were using. Family members were the most common source of information (34\%), followed by the herbalist (25.2\%) (Figure 2). Otherwise, cultural and religious beliefs are the main reasons for the consumption of medicinal plants $(81 \%)$ (Figure 3). 15.5\% rated herbal medicine use as effective, (32.5\%) rated it average, (33\%) little effective and (18.9\%) considered it avoid. 27 patients $(13.1 \%)$ reported side-effects from the (HM) therapy they had used. Most seemed to be digestive.

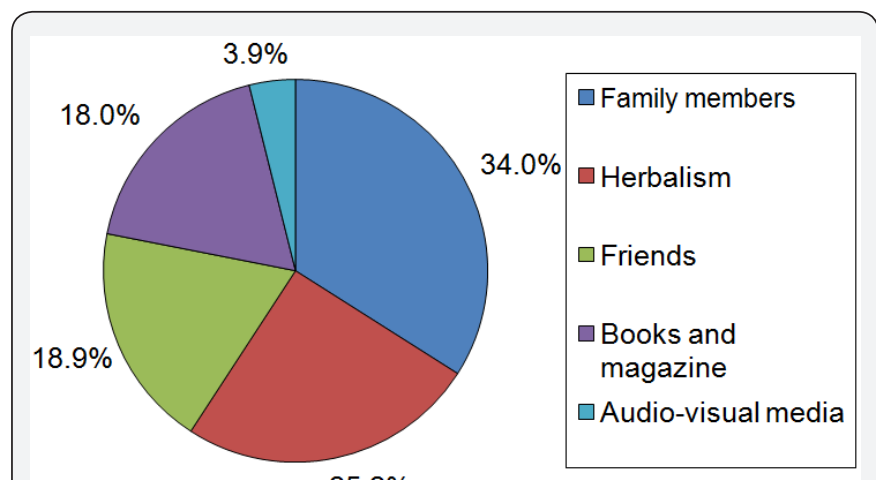

$25.2 \%$

Figure 2: Different types of source information found in our survey.

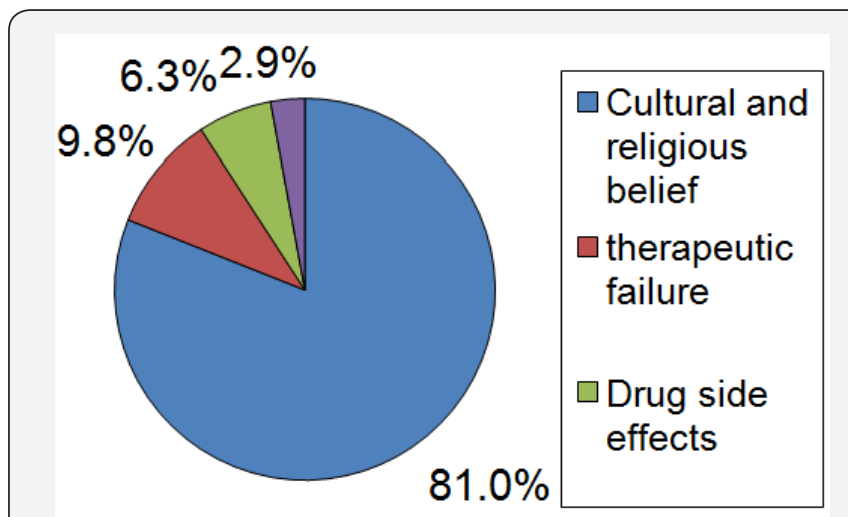

Figure 3: Different reasons found for the consumption of medicinal plants in our survey.

\section{Discussion}

Our survey constitutes the first study in Morocco that focused on herbal medical consumption in the preoperative period. One-quart of our patients admitted to use HM and 13\% have consumed herbal medications within week prior to the surgery. Similar results were found in previous studies. Tsen et al. [9] reported a rate of $22 \%$. Kaye et al. [10] found that $32 \%$ of patients undergoing ambulatory surgery admitted to be HM users. There are several reasons that push to use herbal medicine. Some patients consider them to be natural and therefore safe [11]. Others patient put economic reasons into consideration [12]. Religion and cultural beliefs have been known to play a role
[13] as well as dissatisfaction with the efficacy of conventional medications [14]. In our survey, cultural and religious beliefs are the main reasons for the consumption of medicinal plants, knowing that the majority of consumers are illiterate or have a level of primary school. Pharmacology of many of herbal remedies has yet to be elucidated [9].

In addition, the exact incidence and nature of side-effect from herbal medicines are unknown [15]. However, potential herbanesthetic drug interactions and side effects may cause several complications during perioperative period such as myocardial infarction, stroke, excessive bleeding, delay to wake, organ transplant rejection [16]. Ang-lee and colleagues have identified 8 of the herbs that potentially pose the greatest impact to the care of patients undergoing surgery in the United States [8]. They propose rational strategies for managing the preoperative use of these agents. Although the American Society of Anesthesiologists (ASA) recommends that patients discontinue the use of HM 2-3 weeks before surgery [17]. Anesthesiologists and surgeons must be aware of this importance of this topic [9].

In our study, the most frequently herbs used were Oregano (29.7\%) and Fenugreek (16.1\%). Oregano is widely used in the traditional medicine as lithotriptic, diuretic and antispasmodic along with other medicinal uses, such as stimulant, expectorant, antibacterial, anticancer, anti-inflammatory, antioxidant and laxative [18]. It also contains salicylates, which can mimic some of the anti-platelet effects of aspirin [19]. Caution may be warranted by persons taking prescription anticoagulants to avoid excessive bleeding risk [19] and perioperative bleeding risk should be took into consideration. Fenugreek is a rich source of fibre and has multiple benefits in patient with diabetes [20]. Gupta et al found in their survey that adjunct use of fenugreek seeds improves glycemic control and decreases insulin resistance in mild type- 2 diabetic patients. There is also a favorable effect on hypertriglyceridemia [20]. Although fenugreek has traditionally been considered safe and well tolerated, some side effects have been associated with its use [21]. These effects may especially complicate the preoperative period. Fenugreek contained in curry powder was found to be an allergen in a patient who reported severe bronchospasm and wheezing [22].

Hypoglycemia is an expected effect; therefore, care should be taken to monitor blood glucose [23]. Because fenugreek preparations can contain coumarin derivatives, there is a theoretical risk prothrombin time or the international normalized ratio might be increased, which, in turn, increases the risk of bleeding [24]. Garlic, also found in our survey, claims to be beneficial in cardiovascular disease, diabetes, infection and even tumours. These actions are believed to be because of the cysteine contained in garlic, which decreases thromboxane formation [25]. It causes prolongation of the prothrombin time and increases the international Normalized Ratio (INR) when used in combination with Warfarin therapy [25]. Adverse effects of garlic include nausea, hypotension and allergy. In addition, there have been several case reports of Garlic causing bleeding problems [8]. 


\section{Journal of Anesthesia \& Intensive Care Medicine}

Garlic should also be avoided in patients on aspirin and other nonsteroidal anti-inflammatory drugs (NSAIDs) because it enhances antiplatelet activity.

ASA suggests stopping garlic at least 7 days before surgery [17]. The Lavender was found in our study with a prevalence of $4.9 \%$. Lavender oil is known for its excellent aroma and is extensively used in the perfumery, flavor and cosmetic industries. It is known to possess sedative, carminative, anti-depressive and anti-inflammatory properties. It was also found to be active against many species of bacteria, including those resistant to antibiotics [27]. Its major clinical benefits are on the central nervous system. Many studies conducted on both animals and humans support issues as a sedative, anxiolytic and mood modulator [27]. Most of these effects are thought to result from a facilitation of the action of gamma aminobutyric acid (GABA), an inhibitory neurotransmitter in the central nervous system [27]. In the brain, most of the physiological activities of GABA are generated through GABAA receptors. These ionotropic receptors or ligand-gated ion channel are chloride anion channels that can be opened and activated by the endogenous neurotransmitter GABA and several drug classes including benzodiazepines, barbiturates, steroids, anesthetics and convulsants [27]. Intraoperatively, the combination of these drugs in a patient who uses lavender might further depress the central nervous system. Table 2 summarizes the different plants found in our survey and their preoperative concerns [28].

Table 2: The herbs found in our survey and their perioperative implications.

\begin{tabular}{|c|c|c|}
\hline Name of Herb & Scientific Name & Perioperative Concerns \\
\hline Oregano & Origanum vulgare & Potential to increase risk of bleeding. Might have a diuretic effect. \\
\hline Fenugreek & Trigonella foenumgraecum & $\begin{array}{l}\text { Interferes with antidiabetes drugs, it might cause hypoglycemia. Potential to increase } \\
\text { risk of bleeding, especially when combined with other medications that inhibit platelet } \\
\text { aggregation. }\end{array}$ \\
\hline Verbena & Verbena officinalis & No data available. \\
\hline Chamomile & Matricaria chamomilla & No data available. \\
\hline Rosemary & Rosmarinus officinalis & $\begin{array}{c}\text { Contains a chemical that is very similar to aspirin. Potential to increase risk of } \\
\text { bleeding. }\end{array}$ \\
\hline linseed & Linum usitatissimum & Potential to increase risk of bleeding. Might cause hypoglycemia and hypotension. \\
\hline Nigella Sativa & Nigella sativa & $\begin{array}{l}\text { Hypoglycemia. Potential to increase risk of bleeding Potential to increase sedative } \\
\text { effect of anesthetics. }\end{array}$ \\
\hline Garlic & Allium sativum & $\begin{array}{l}\text { Potential to increase risk of bleeding, especially when combined with other } \\
\text { medications that inhibit platelet aggregation. }\end{array}$ \\
\hline Caraway & Carum carvi & Interfères with antidiabetes drugs; it might cause hypoglycemia. \\
\hline Tooth Lavender & Lavandula dentata & Potential to increase sedative effect of anesthetics. \\
\hline Pennyroyal & Mentha pulegium & Nephrotoxic. \\
\hline Green anise & Pimpinella anisum & No data available. \\
\hline Honey of Euphorbia & Euphorbia mellifera & No data available. \\
\hline Ginger & Zingiber officinale & Potential to increase risk of bleeding. \\
\hline Sage & Salvia officinalis & Interfères with antidiabetes drugs; it might cause hypoglycemia. \\
\hline Coriander & Coriandrum sativum & Interfères with antidiabetes drugs; it might cause hypoglycemia. \\
\hline Myrtle Common & Myrtus & Might cause hypotension. \\
\hline Clove & Syzygium aromaticum & Potential to increase risk of bleeding. \\
\hline Olive Leaf & Olea europaea & $\begin{array}{l}\text { Antidiabetes drugs and antihypertensive drugs interact with olive. It might cause } \\
\text { hypoglycemia and hypotension. }\end{array}$ \\
\hline Parseley & Petroselinum crispum & $\begin{array}{l}\text { Nephrotoxic. Hypoglycemia. It might cause a sodium retention and this could make } \\
\text { high blood pressure worse. }\end{array}$ \\
\hline Mercury Herb & Mercurialis annua & No data available. \\
\hline White Horehound & Marrubium Vulgare & It might cause hypoglycemia and hypotension. \\
\hline Aristoloche & Aristolochia & It might bring on early kidney failure in people with kidney disease. \\
\hline
\end{tabular}


More than $70 \%$ of the patients in the study by Kaye and al failed to disclose their herbal medicine use during routine preoperative assessment [10]. Some possible reasons for nondisclosure are that patients may believe that physicians are not knowledgeable about or are prejudiced against herbal medicine usage [10]. Some patients may fear admitting to their physicians their use of unconventional therapies [8]. Others may neglect to mention that they are taking herbal medications when they are using them for reasons perceived as unrelated to their medical care [29]. In our survey, admit of HM consumption was not spontaneous, but rather caused by our questionnaire. Because most patients may not volunteer that they taking herbal medications in the preoperative evaluation, the obligation therefore lie on healthcare practitioners to elicit history of herbal use during preoperative assessment, and anesthesiologists should become familiar with the names, indications and actions of the most commonly used agents.

There are several limitations in our study. There is a single center study and patients enrolled in our survey may therefore not be representative for Moroccan surgical population. A more extensive and multi-center survey focuses on HM consumption in surgical patients is needed in the future. In addition, we didn't follow our patients during surgery, which does not allow us to ensure any complications related to HM use. However, we perform the first prospective survey in Morocco that focused on HM consumption in the preoperative period.

\section{Conclusion}

A significant proportion of presurgical patients use alternative therapies in our survey. Admits to this consumption is not often spontaneous. Many of these agents lead to increased risk of perioperative bleeding, and toxicity on almost all the systems has been reported and our knowledge of the pharmacodynamics and pharmacokinetic properties of many of the herbal medications is incomplete. Future studies are needed to better define these issues. In addition to discontinued the herbal medicines two to three weeks before an elective surgical procedure to avoid potential intraoperative catastrophic events, we suggest that detailed history of usage of herbal products might be recorded and made a routine part of the preanesthetic evaluation and that anesthesia care providers should be educated about herbal medicines and familiar with their potential side effects.

\section{Competing Interests}

The authors declare that they have no competing interests.

\section{Funding}

Special thanks to the Faculty of Medicine and Pharmacy of Rabat; the source of funding for all authors.

\section{Acknowledgement}

All the authors are thankful for providing the necessary facilities for the preparation the manuscript.

\section{Ethics Approval and Consent to Participate}

Applicable.

\section{References}

1. Bauer BA (2000) Herbal therapy: what a clinician needs to know to counsel patients effectively. Mayo Clin Proc 75(8): 835-41.

2. Eisenberg DM, Kessler RC, Foster C, Norlock FE, Calkins DR, et al. (1993) Unconventional Medicine in the United States -Prevalence, Costs, and Patterns of Use. N Engl J Med 328(4): 246-252.

3. Drew AK, Myers SP (1997) Safety issues in herbal medicine: implications for the health professions. Med J Aus 166(10): 538-41.

4. Harrison RA, Holt D, Pattison DJ, Elton PJ (2004) Who and how many people are taking herbal supplements? A survey of 21,923 adults. Int J Vitam Nutr Res 74(3):183-186.

5. Barrett B, Kiefer D, Rabago D (1999) Assessing the risks and benefits of herbal medicine: an overview of scientific evidence. Altern Ther Health Med 5(4): 40-49.

6. Falodun A (2010) Herbal medicine in Africa-Distribution, standardization and prospects. Research journal of phyto chemistry 4: 154-161.

7. Batra YK, Rajeev S (2007) Effect of common herbal medicines on patients undergoing anaesthesia. Indian J Anaesth 51(3): 184-192.

8. Ang Lee MK, Moss J, Yuan CS (2001) Herbal medicines and perioperative care. JAMA 286(2): 208-216.

9. Tsen LC, Segal S, Pothier M, Bader AM (2000) Alternative medicine use in presurgical patients. Anesthesiology 93(1): 148-151.

10. Kaye AD, Clarke RC, Sabar R, Vig S, Dhawan KP, Hofbauer R et al. (2000) Herbal medicines: current trends in anesthesiology practice--a hospital survey. J ClinAnesth 12(6): 468-471.

11. King AR, Russett FS, Generali JA, Grauer DW (2009) Evaluation and implications of natural product use in preoperative patients: a retrospective review. BMC Complement Altern Med 9: 38.

12. Collins D, Oakey S, Generali JA, Grauer DW (2011) Perioperative Use of Herbal, Complementary, and Over the Counter Medicines in Plastic Surgery Patients. Eplasty 11: e27.

13. Ezejiofor NA, Maduagwunan C, Onyiaorah VI, Hussaini DC, Orisakwe OE (2008) Multiple organ toxicity of a Nigerian herbal supplement (U \& D Sweet bitter) in male albino rats. Pak J Pharm Sci 21(4): 426-429.

14. Ernst E, Pittler MH (2002) Herbal medicine. Med Clin North Am 86(1): 149-61.

15. Barnes J, Mills SY, Abbot NC, Willoughby M, Ernst E (1998) Different standards for reporting ADRs to herbal remedies and conventional OTC medicines: face-to-face interviews with 515 users of herbal remedies. Br J Clin Pharmacol 45(5): 496-500.

16. Perharic L, Shaw D, Murray V (1993) Toxic effects of herbal medicines and food supplements. Lancet 342(8864): 180-181.

17. Leak JA (2000) Herbal medicines: what do we need to know? ASA Newsletter. 2000: 64.

18. Khan A, Bashir S, Khan S R, Gilani A H (2011) Antiurolithic activity of Origanum vulgare is mediated through multiple pathways. BMC Complementary and Alternative Medicine 11: 96.

19. Garry G, Duthie, Adrian D Wood (2011) Natural salicylates: foods, functions and disease prevention. Food Funct 2(9): 515-520.

20. Gupta A, Gupta R, Lal B (2001) Effect of Trigonella foenum-graecum (fenugreek) seeds on glycaemic control and insulin resistance in type 
2 diabetes mellitus: a double blind placebo controlled study. J Assoc Physicians India 49: 1057-1061.

21. Basch E, Ulbricht C, Kuo G, Szapary P, Smith M (2003) Therapeutic applications of fenugreek. Altern Med Rev 8(1): 20-27.

22. Ohnuma N, Yamaguchi E, Kawakami Y (1998) Anaphylaxis to curry powder. Allergy 53(4): 452-454.

23. Sharma RD, Raghuram TC (1990) Hypoglycaemic effect of fenugreek seeds in non-insulin dependent diabetic subjects. Nutr Res 10: 731739 .

24. Lambert JP, Cormier A (2001) Potential interaction between warfarin and boldo-fenugreek. Pharmacotherapy 21(4): 509-512.

25. Wong A, Townley SA (2011) Herbal medicines and anaesthesia. Continuing Education in Anaesthesia Critical Care \& Pain. 11(1): 1417.

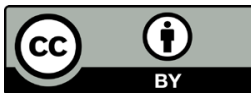

This work is licensed under Creative Commons Attribution 4.0 License

DOI: $10.19080 / J A I C M .2018 .05 .555659$
26. Heck AM, DeWitt BA, Lukes AL (2000) Potential interactions between alternative therapies and warfarin. Am J Health Syst Pharm 57(13): 1221-1227.

27. Babahedari AK, Faraji S, Soureshjani EH (2014) A Comparative Molecular Docking study of Lavandula Angustifolia Mill's compounds Along Diazepam and Amobarbital with GABAA Receptor. Int'l Journal of Advances in Chemical Engg \& Biological Sciences l(1).

28. Vitamins and supplements center.

29. Elder NC, Gillcrist A, Minz R (1997) Use of alternative health care by family practice patients. Arch Fam Med 6(2): 181-184.

\section{Your next submission with Juniper Publishers} will reach you the below assets

- Quality Editorial service

- Swift Peer Review

- Reprints availability

- E-prints Service

- Manuscript Podcast for convenient understanding

- Global attainment for your research

- Manuscript accessibility in different formats

( Pdf, E-pub, Full Text, Audio)

- Unceasing customer service

Track the below URL for one-step submission https://juniperpublishers.com/online-submission.php 